\title{
Transformación de la imagen de los Wixaritari (Huicholes) en el imaginario teiwari (mestizo, foráneo)
}

Jorge Luis Marín García

(Universidad Autónoma de

Nayarit)

\section{INTRODUCCIÓN}

Aunque no es la forma usual, para volver más claro el texto, se comenzará explicando dos categorías (sustantivos, a veces adjetivos) que se utilizarán de forma continua en el documento: wixarika y teiwari.

Wixarika (pl. wixaritari) es el endoetnónimo utilizado por el grupo indígena mexicano generalmente conocido como huichol entre la mayoría de la población mestiza mexicana y aún en planos internacionales, a final de cuentas, lo wixarika es hablar de reconocido como propio por los miembros de del tal grupo humano. De ese modo, cuando en este texto se habla de wixarika o wixaritari nos estaremos refiriendo o bien a personas integrantes del grupo o bien a cosas o prácticas culturales identificadas como de origen wixarika'.

Teiwari (pl. teiwarixi), por su parte, es en principio lo que se reconoce como foráneo, que proviene del exterior de la cultura wixarika, exceptuando a quienes y lo que proviene de los grupos indigenas vecinos como los naayerij (coras), audam y o' dam (tepehuanes del sur) o los mexicaneros, quienes son nombrados por sus etnónimos. Generalmente, teiwari es la forma de referirse al vecino, el mestizo mexicano, aunque también lo es para extranjeros. En ese sentido, cuando se hable de teiwari o teiwarixi, nos estaremos refiriendo a personas, prácticas culturales o cosas cuyo origen es considerado como distinto al del grupo wixarika y que tampoco tienen su origen en los grupos indígenas más cercanos a ellos.

Dentro de distintas disciplinas de las ciencias sociales y humanas, pero especialmente en la antropología y desde un punto de vista eurocéntrico, en ciertos momentos de la historia se ha hablado de pueblos primitivos y pueblos civilizados, sociedades simples y sociedades complejas, tribus y estados, sociedades modernas y sociedades premodernas, salvajes y civilizados; y hasta se ha dividido a la humanidad en pueblos sin historia y pueblos con historia, aunque se hable de pueblos que conviven en un mismo tiempo y espacio. Así 
es como se ha conformado el mundo en el imaginario de distintas sociedades, sin excluir una gran parte de la población mexicana.

El problema de reproducir un esquema de pensamiento donde sin preguntarse más se divide a la humanidad en modernos y premodernos o primitivos y civilizados, es que se parte de un enfoque epistemológico erróneo al considerar, a veces de manera inconsciente, que un grupo de seres humanos que está en constante interacción con sus "Otros" pueda tener prácticas culturales que no cambian como si una omnipotencia desde el inicio de los tiempos hubiera dictado que tal o cual forma de cultura pertenecería a un grupo humano en específico y así permanecería, sin transformaciones hasta el fin de los tiempos. Con ello se ignoran o minimizan prácticas interculturales que se hayan querido o no por alguna de las partes, han resultado de procesos histórico-económicopolítico- culturales. Así, a partir de ideas románticas del buen salvaje o desde el enfoque del indio-problema, se crean y recrean imaginarios ignorando las transformaciones de las sociedades, y se establece un proceso de al menos una parcial deshumanización para los respectivos "Otros" pues se les niega una característica reconocida como esencialmente humana: la transformación de la sociedad y la cultura. Así es como en innumerables ocasiones se ha hablado y escrito sobre los wixaritari, su cultura, territorio y arte. Sobre críticas a esas dicotomías véase (Pratt 1996; Pérez 2005; Rivera Cusicanqui 2010).

\section{WIXARITARI, TERRITORIO E INTERCULTURALIDAD}

Los wixaritari son un pueblo indígena del noroccidente de México si se considera que se pueda constreñir tal pueblo al territorio que generalmente le reconocen como propio, dentro de la región del Gran Nayar, en un área que va de 4100 a $4107.5 \mathrm{Km} .2$, ubicada entre los $21^{\circ} 40^{\prime}$ y $22^{\circ} 30^{\prime}$ de latitud norte y $104^{\circ} 30^{\prime}$ y $103^{\circ} 50^{\prime}$ longitud oeste, abarcando parte de cuatro estados: Durango, Jalisco, Nayarit, y Zacatecas. Sin embargo, si se toman en cuenta sus prácticas culturales, hablaríamos de un pueblo cuyo territorio se extiende más allá del noroccidente de México, a lo largo de aproximadamente $90000 \mathrm{Km} .2$, que abarca Durango, Jalisco, Nayarit, Zacatecas, y San Luis Potosí (ver al respecto Fresán 2001; Liffman 2005; Neurath y Pacheco Bribiesca s/d).

Bajo otras lógicas, el territorio wixarika puede extenderse hasta lugares como el Cañón de Guitarritas en el estado de Nuevo León o la ciudad de México, por mencionar algunos espacios. Al respecto, escribe Neurath:

Muchas veces la emigración equivale a una expansión del territorio comunal. La fundación de nuevas comunidades crea la necesidad de organizarse nuevos centros ceremoniales. Paralelamente "descubrimientos" recientes de lugares sagrados por parte de los chamanes huicholes abren nuevos horizontes a la "geografía ritual". Entre los lugares sagrados de los huicholes actualmente se encuentran las ruinas de Teotihuacan, el Museo Nacional de Antropología, una piedra en las faldas de volcán Iztaccíhuatl y otras en los alrededores de Tepoztlán, así como la roca con petrograbados que asemeja a un águila en las Guitarritas, Nuevo León.

L]os mara'akate descubren nuevos lugares sagrados en los alrededores de los centros urbanos y turísticos donde los Huicholes suelen vender artesanías (Neurath 2002: 26 y 80 citado por Beimborn y Romandía 2009: 23).

Como puede leerse en el texto de Neurath, al menos entre líneas, la territorialización de este grupo indígena parte de las redes tejidas por los wixaritari desde los tiempos en que no se tiene memoria hasta esta época, 
gracias en gran parte al binomio wixaritari-arte huichol que viene desde el imaginario católico español al chamánartista huichol de la segunda mitad del siglo XX. Habrá entonces que decir al lado de Beimborn y Romandía que

la migración juega un papel de primer orden en [la] cultura, así como en la vida social del huichol; entre tantos otros aspectos: por una parte, a razón de las diversas dinámicas entre emigrantes y las comunidades de la sierra; y por otra, debido a ser ésta una arena esencial y rica de distintas prácticas y reflexiones de la Id-entidad. (Beimborn y Romandía 2009: 14)

Y en ese sentido, aunque no específicamente analizado aquí, el fenómeno migratorio entre los wixaritari

[...] debe ser tratado como una parte constitutiva de dicho pueblo. Y ello no sólo a razón de que el capital llevado a la sierra apoya en gran medida la continuación de la vida "tradicional" en aquellas latitudes; por decirlo así, es en el corazón de la cultura donde se reproduce. Más aún, porque la migración es un fenómeno tan común entre grupos huicholes desde hace tiempo [...] En lugar de entender a los huicholes como sobrevivientes en lejanas montañas aisladas, vemos una imagen de ellos como actores en varias arenas, quienes activamente reproducen su cultura contacto con el mundo globalizado (idem).

Se coincide pues con Beimborn y Romandía en la idea de que la conservación de muchas prácticas culturales antiguas entre los wixaritari es dada por el contacto con sus múltiples "Otros" y no por la tesis del aislamiento compartida por investigadores como Lumholtz (1904, 1986), Zingg (1982 [1938]), Soto Soria (1955), Benítez (1968), Furst y Nahmad (1972), Reed (1972) Myerhoff (1974) y Berrin (1978), entre otros, para quienes los wixaritari son un grupo que ha conservado muchas de sus prácticas culturales anteriores a la conquista española gracias al aislamiento por el difícil acceso de su territorio, o por su cerrazón a las culturas "Otras". Si se considera que en sus prácticas culturales actuales se encuentran muchos elementos prehispánicos, también se debe tener en cuenta que no son prácticas congeladas, sino con adecuación a los contextos de economía, lugar, política, religión y tiempo

El objetivo de este trabajo es dar a conocer la manera en que ha ido cambiando la imagen de los wixaritari en el imaginario teiwari, con base en las relaciones que han ido estableciendo unos con otros, no necesariamente pacíficas sino más bien problemáticas porque el punto de arranque del encuentro de ambas sociedades ha sido el de un grupo conquistador que se imagina superior e intenta sojuzgar, y el de otro grupo de seres humanos cuya mayor resistencia ha sido la de saber conocer los términos del otro y negociar para poder conservar al menos parcialmente su territorio y llevar a cabo sus prácticas culturales que los identifican precisamente como grupo distinto culturalmente a otros. Como escribe Neurath:

La lucha huichola por defender su autonomía no se manifiesta en conflictos políticos abiertos con el exterior [...] Lo que no permiten es que representantes de una instancia externa, gubernamental o no-gubernamental lleguen a controlar aspectos importantes de la vida comunitaria. (Neurath 2011: 121)

De hecho, el arte huichol y el desarrollo del ciclo ritual anual, han sido dos de sus mayores prácticas de resistencia y negociación en la que el imaginario ha jugado un importantísimo papel, especialmente cuando se han convertido en dos de las facetas más visibles de los wixaritari y les han ganado importantes aliados entre 
la población teiwari, en relaciones a veces ambivalentes por la búsqueda de autonomía ya descrita. Todo ello demuestra precisamente una sociedad en transformación y no una que permanece en el mismo estado a lo largo del tiempo.

En un intento por hacer más claros los cambios que ha tenido la imagen de los huicholes en el imaginario mestizo y extranjero, el trabajo se divide en 3 partes principales: la primera, Los wixaritari en el imaginario teiwari de la época colonial y primer siglo del México independiente, busca establecer cómo se transformó la imagen del huichol en el imaginario español y mestizo desde los primeros contactos hasta la época de la Reforma y principios del porfiriato. En la segunda, El "descubrimiento" de los wixaritari como tribu de artistas. Extranjeros por el territorio wixarika a finales del siglo XIX y primera mitad del siglo XX, se pretende dar cuenta de la influencia que tuvieron algunos investigadores extranjeros, distintos a los hispanos, en la transformación de la imagen del huichol en el imaginario teiwari, sobre todo en décadas posteriores a la publicación de sus trabajos. En la parte última, El "redescubrimiento" de los wixaritari como "tribu de artistas" por el Estado mexicano a la segunda mitad del siglo XX se intenta narrar la forma en que el estado mexicano se adentra en la cultura de los huicholes y valora positivamente una de su prácticas culturales ya reconocida por cierto sector académico del extranjero para ese tiempo: el arte; lo que conlleva a nuevas construcciones de la imagen del wixarika en el imaginario teiwari. Se debe señalar que en este documento, siguiendo a Lumholtz (1986), arte es la demostración del dominio de la técnica en la elaboración de los objetos y el complejo uso del símbolo en las representaciones huicholas. ${ }^{2}$

\section{LOS WIXARITARI EN EL IMAGINARIO TEIWARI DE LA ÉPOCA COLONIAL Y PRIMER SIGLO DEL MÉXICO INDEPENDIENTE}

Aunque investigadores como Ramírez (1980) y Gerhard (1996), apoyándose en información de los primeros cronistas españoles de la región ubican la cultura huichola diseminada a lo largo y ancho de los 4 puntos cardinales de Nayarit, norte y noreste de Jalisco en sus fronteras con Nayarit y Zacatecas, se debe decir que toman como huicholes o antepasados de ellos a grupos que los cronistas mencionaron con nombres distintos a huichol a lo largo del siglo XVI: xurutes, uzares o vizuritas (Tello 1946; De Ciudad Real 1976; Ponce 1976; Rojas 1992 y 1993). ${ }^{3}$ Además de lo anterior, también se toma en cuenta que por aquellas épocas también se habla de la existencia de una "lengua guichola" y de la presencia de "guisoles en el Nayarit" (Ruiz Colmenero 1652 en Santoscoy 1899: LIX) o de huitzolmes (Saavedra 1672 en Santoscoy 1999: 28), palabras más cercanas fonéticamente al nombre más conocido de ellos, huichol. ${ }^{4}$

De ese modo, es muy posible que los misioneros de los tempranos años de la conquista del Gran Nayar, a los miembros de un mismo grupo cultural, el wixarika, les dieran los distintos nombres ya mencionados. Por otra parte, también es posible que distintos grupos como los ya mencionados, al avance de la conquista española se integraran en uno, el wixarika. Lo que sí es seguro es que el grupo wixarika ha ido integrando elementos de distintas culturas con las que ha tenido contacto a lo largo del tiempo y así es como lo conocemos, sin dejar de lado que también se han construido disímiles formas de imaginarlo. 


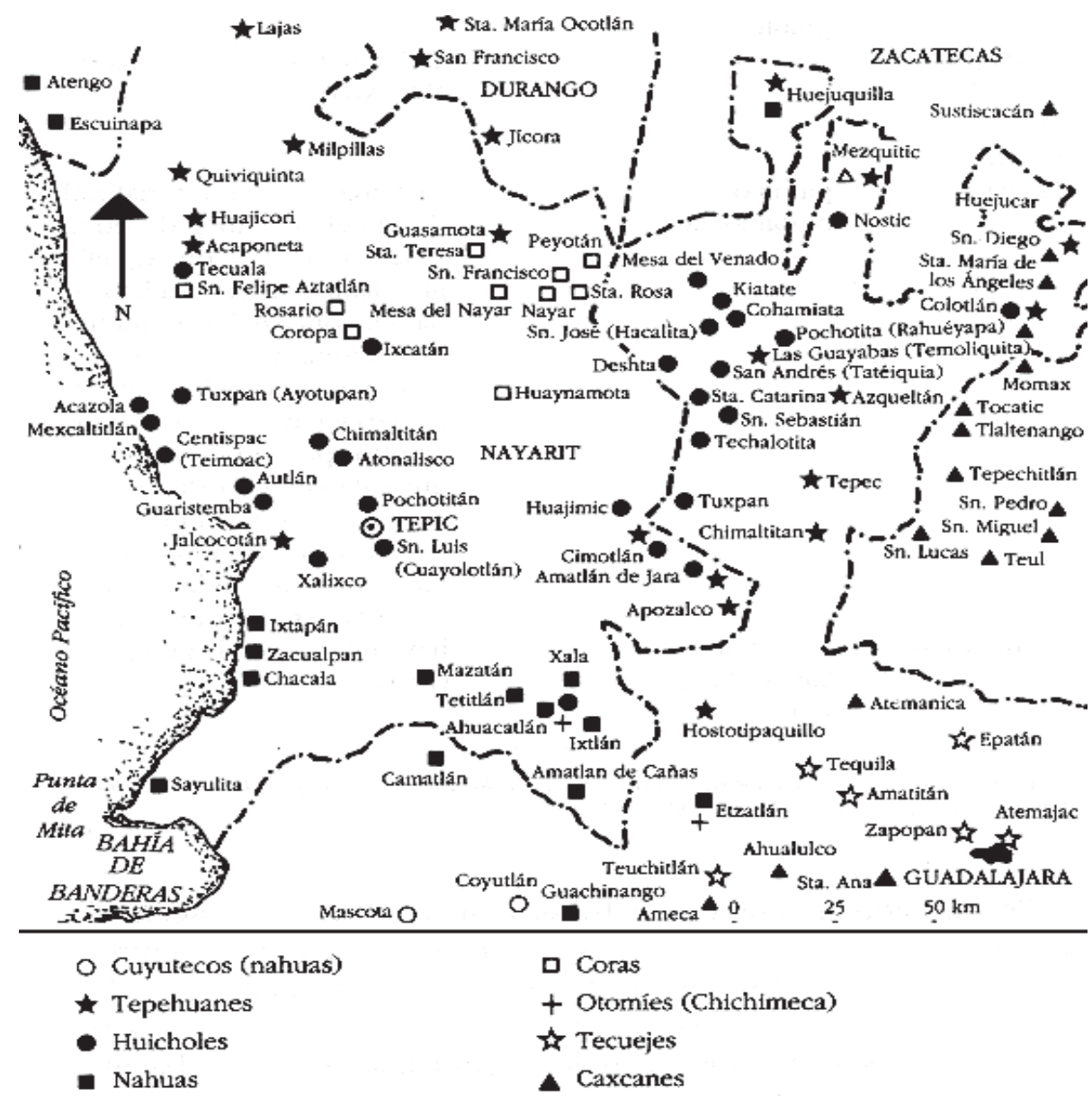

Fuente: http://bibliotecadigital.ilce.edu.mx/sites/estados/libros/nayarit/html/sec_22.html. Fecha de última consulta 15 de mayo de 2013.

En ese sentido, lo que hoy se admira como parte de la cultura wixarika, alguna vez fue motivo de preocupación, indignación, y hasta pretexto para quitarles la vida y sus posesiones, desde la llegada de los conquistadores españoles hasta tiempos no muy lejanos de nuestros días. La construcción del indio, y del wixarika en particular en el imaginario no indígena ha consistido generalmente en la descripción de aspectos seleccionados de su vida, de acuerdo con los parámetros del observador. Así lo hicieron los primeros religiosos y demás conquistadores españoles a su llegada al Gran Nayar cuando se enfrentaron a maneras de ver y vivir el mundo, y de relacionarse con lo sagrado fuera del canon católico. Por eso, las escenas contempladas en el 
territorio indígena sin catequizar los horrorizaba y la otredad era vista como infrahumana. Así, Antonio de Ciudad Real nos lega su visión sobre los antiguos huicholes, llamados por él uzares, en su Tratado curioso y docto de las grandezas de la Nueva España, por lo que le tocó ver en 1587 acompañando a fray Alonso Ponce, Comisario General de la Orden Franciscana:

A la parte del oriente tiene otra provincia que se dice de los uzares, la cual es muy estéril en los frutos de la tierra; cogen muy poco maíz, y aunque son todos idólatras no tienen adoración común sino cada uno elige el ídolo y le aplica aquello que más le inclina la naturaleza; comen carne humana y dicen ser hasta mil hombres... (De Ciudad Real 1976: 100).

El ámbito geográfico donde encontraron los primeros misioneros a los ancestros de los huicholes ha sido parte fundamental del cómo la imagen del wixarika se ha ido construyendo. Una zona montañosa con distintos nichos ecológicos, difícil de atravesar para los teiwarixi, a la que se aunó la manera de territorializarla por parte de los moradores: rancherías habitadas por pequeños grupos familiares a quienes costaba mucho trabajo convencer de que se reunieran en poblados para poder adoctrinarlos en la fe cristiana; y cuando lograban hacerlo, al poco tiempo casi todos volvían a la forma wixarika de habitar el territorio. Si bien es cierto que los religiosos no formaron parte de la primeras incursión de los exploradores españoles en el territorio actualmente wixarika, ${ }^{5}$ pronto tuvieron contacto con los xurutes, uzares o vizuritas, (Rojas 1992: 23), en lugares como Tepic, Sombrerete, Fresnillo o Zacatecas, puntos importantes de las rutas recorridas por los huicholes y otros indígenas en el comercio de la sal. Además, los padres franciscanos hacían algunas incursiones en territorios inexplorados buscando catequizar a los indígenas como atestigua Tello en el caso de fray Pedro del Monte quien desde la provincia de Xalisco se adentró hasta Amatlán y Xora -ambos poblados del actual estado de Nayarit- permaneciendo allí por siete meses hacia 1580 (Tello 1946: 103-104 en Rojas 1993: 48).

Al lado de la catequización para acabar con el maligno aposentado en las tierras nayaritas, los conquistadores también implementaron, en la medida de sus posibilidades, las herramientas necesarias para que los indígenas ingresaran al sistema económico deseado por los colonizadores, apoyándose en indios aliados. Acelia García, basada en el trabajo de Alonso de la Mota y Escobar, describe que hacia 1559 San Luis de Colotlán fue poblado con

españoles y tlaxcaltecas, junto con indígenas recién pacificados. Los tlaxcaltecas fueron colocados en un barrio para que vivieran junto con chichimecas [...] para así enseñarles varios trabajos tales como arar la tierra, sembrar, cosechar, guardar las cosechas en sus graneros, domar caballos y mulas de carga, tratar con personas [...] los tlaxcaltecas estaban impartiendo clases de cultura material que incluían el tejido de cintura y el hilado, lo cual quiere decir que los textiles de lana principiaron entre los coras y huicholes de Colotlán en ese entonces (García de Weigand 2002: 118-119).

Lo que García de Weigand describe es un ejemplo de la manera en que grupos distintos a los wixaritari pudieron influir en el desarrollo de su cultura mediante imposiciones que al tiempo se convirtieron en apropiaciones culturales. También desde tempranos años ya se conoce de algunos de los objetos que usaban como adorno algunos de los indígenas del Gran Nayar, por ejemplo, en Amatlán (actualmente Amatlán de Jora, mpio. De La Yesca), hacia 1620: 
en sus costumbres estaban tan gentiles como sus antepasados, porque no sabían la doctrina christiana, y se casaban con dos y tres mujeres, y traían gargantillas y zarcillos, y los cabellos tan largos que les llegaban a las rodillas y con corvas, / aunque algunos los traían trançados [...] (Tello 1946: 359-360)

Hacia el siglo XVIII el contacto entre huicholes y mestizos se volvió más frecuente y, las visitas de los misioneros al territorio wixarika crecieron en número, pero sólo por cortos periodos de cierto tiempo al ser interrumpidos por la violencia, expresión de rechazo a la presencia de "mexicanos" y españoles en El Gran Nayar. No obstante, para esa época los indios ya habían aprendido no sólo a conocer lo que eran sus "Otros" sino lo que esperaban esos "Otros" de ellos. Por ejemplo, mientras que a cierta fecha (julio de 1702) se levantaban contra el Capitán Protector Silva en gran número de sublevados; luego de darle muerte, enviaban cartas a las autoridades, entre ellas el rey, reiterándoles su fidelidad y dando gracias por el cristianismo: así obtenían el perdón. Nuevamente se levantaban y nuevamente pedían perdón. Es decir, habían aprendido el sistema político y de justicia coloniales, haciendo competente uso de él. Los gobernantes, por su parte, también aprendieron el sistema indígena y el perdón llegaba (en ocasiones después de una gran matanza y esclavizar personas) pues los huicholes y otros grupos representaban la defensa del territorio ya domesticado (Rojas 1992: 44-50)

Empero, por lo que se puede ver en los documentos que nos legaron los misioneros, la mayor parte de los integrantes de esta etnia se negaron a congregarse en pueblos y por lo tanto la catequización y otras formas de educación resultaron difíciles de lograr, a excepción de algunos contados casos. Un ejemplo es lo relatado por Lázaro de Arrégui:

Adminístranles la doctrina dos religiosos de San Francisco que asisten entre ellos [...] Que cada día se les van a sus rancherías de donde no los pueden sacar hasta que ellos se vienen, y apenas vienen unos cuantos se van otros. Y tal vez se van que no queda nadie en el pueblo sino los padres y algunos que les sirven, como sucedió en el año de 1617. (Lázaro de Arreguí 1980).

Aunado a no querer formar poblados como lo solicitaban los conquistadores, los indígenas del Nayarit -otra forma de llamar a El Gran Nayar-, y especialmente los serranos huicholes, seguían adorando a numerosos entes diabólicos desde el punto de vista de los misioneros. Así lo atestigua Lázaro de Arregui sobre una visita que hizo a los conventos de la provincia de Huejuquilla - actual estado de Jalisco-, parte del territorio cultural de los huicholes entre los años 1725 y 1728 :

visitando los conventos de esta sierra, el ministro me trajo una rodela bordada de abalorios, que tenía en la mano un ídolo colocado en nuevo templo que estaba fabricado en lo profundo de una barranca, con otros ídolos pequeños que eran propia representación del demonio (Santoscoy 1986: 41 citado en Rojas 1992: 74-75).

Lo "demoniaco" predominaba en las artes de los huicholes como también observó Covarrubias en un templo de los indígenas, por la misma zona visitada por De Arreguí:

En lo restante de aquel diabólico templillo [...] se veían, dispuestas con descompasado orden, diversas figuras de animales; [...] se admiraban enarbolados, curiosísimos y distintos pendones de guerra [irodelas?, inierikate? ]; colgaduras de diversos colores y hechizos, todas de algodón, en gran número; servían al trono tapetes y alfombras 
de la misma materia y curiosidad; en los cuatro ángulos del adoratorio se veían, en gran cantidad diversidad de flechas que distintas naciones circunvecinas tributaban a este demonio (Meyer 1989: 62-68 en Rojas 1992: 75).

Pese a los deseos porque los huicholes y otros grupos dejaran de adorar al demonio, dos circunstancias obligaron a moderar el uso de las armas tan común en la conquista espiritual de aquella época. La primera, una cédula real de 1709 por la que se instaba a conquistar con "suavidad y dulzura", como describe Torres

para inicios del siglo XVIII, Antonio Margil de Jesús, por indicaciones de la corona, plasmadas en la Real Cédula del 31 de julio de 709 [...] instó a la Real Audiencia [...] para que la penetración y conquista se hiciese con 'suavidad y dulzura'. Se le mandó una carta a todos los indios nayaritas, anunciándoles la Real benignidad con que se les perdonarían todos los delitos que hubiesen cometido en cualquier tiempo y todas las penas que mereciesen los refugiados en sus territorios, más la libertad a los esclavos fugitivos. A todos se les concedían privilegios y exenciones (Torres 2000: 44-45).

Inicialmente los indígenas se negaron, pero al final aceptaron la propuesta pues los españoles les habían cerrado las puertas para el comercio de la sal que era una de sus actividades económicas principales.

Entre los acuerdos que tuvieron pidieron que se les había de amparar su posesión de las tierras, guardándoles perpetuamente sus privilegios a sus descendientes y fueros y que a los demás caciques y sus descendientes se les habían de guardar los fueros correspondientes y nunca habían de pagar tributo, y no habían de conocer otro juez en sus causas, que los señores virreyes. Que habían de tener paso libre para el pueblo de Acaponeta y Mescaltitlán (sic), a cargar sal para su provincia, sin pagar alcabala ni otra pensión por lo que comerciasen. Que los indios de los suyos que estaban presos en el pueblo de Colotlán y otros dos en la cárcel de la corte de Guadalajara, habían de salir de prisión libres [...] estudiáronse las propuestas en junta de guerra y sin desdoro de su majestad fueron aceptadas el 20 de marzo de 1721 (Torres Contreras 2000: 46).

La segunda circunstancia, derivada de la primera, fue que los indios de la frontera chichimeca de San Luis Colotlán, Jalisco entre los que se encontraban los huicholes, se convirtieron en "milicianos", indios flecheros aliados que defendieron el territorio "civilizado" de los indios "Otros" que no aceptaban la forma de civilización española, los chichimecas. A cambio, se les eximió de las encomiendas y de los tributos que los otros indios tenían, aunque nunca faltó el hacendado que quisiera hacerse de más tierras. ${ }^{6}$

Los jesuitas, quienes se habían hecho cargo de la evangelización del territorio del Nayarit a finales del siglo XVI, fueron expulsados en 1767 y los franciscanos quedaron a cargo del territorio. Años después, la situación de los wixaritari respecto a lo religioso, al menos desde el punto de vista de los "mexicanos", no había cambiado gran cosa. Dice Felix Calleja sobre su visita a la región en 1790:

Estos indios no reciben otro sacramento que el del baptismo, si se le administra de balde, y aun así, no todos. Se casan y descasan entre sí siempre que les dé la gana, no oyen missa y si alguna ve a persuasión del religioso, entran a la iglesia, no permanecen en ella más tiempo que el sacerdote tarda en ponerse al altar [...] Estos como todos los de lo áspero de la sierra madre, se conservan en la idolatría, dando culto y hasiendo funciones públicas a sus ídolos. (Diario formado por el capitán de infantería don Félix Calleja, AGI, Guadalajara: 393 en Rojas 1992: 102).

Más tarde, en 1848, a cinco años del regreso de los franciscanos a la sierra, luego de más de 30 años de haberla abandonado, fray Felipe de Jesús María Muñoz observó que los indios de San Andrés Cohamiata 
adoraban a dioses de la naturaleza, el sol y la luna, “el pollo u el venado la vaca y otros [...] según los monos y las figuras que le he podido encontrar en los Aliguelles (casas de idolatría) y otros lugares escondidos" (Documento del Archivo Histórico de Zapopan; en Rojas, 1992: 139-140). También nos revela algún aspecto de la zona de contacto para esos años entre los "aislados" huicholes y mestizos:

donde resultan ciertas reuniones que me he encontrado formadas de estos pueblos con otros y con los que llama de razón que por desgracia son hombres corrompidos cuyas reuniones jusgo se van compactando y haciendo más dificultosa la reducción de estas tribus... (Documento del Archivo Histórico de Zapopan en Rojas 1992: 139-140).

Asimismo, ese escrito da cuenta del saqueo de los bosques y el robo de las tierras de los wixaritari por parte de mestizos y españoles en los primeros años de la Independencia. No obstante, mientras los representantes de la corona española gobernaron el occidente de México y demás partes de la América hispana, los límites del territorio de los huicholes se mantuvieron relativamente constantes. Como señala Liffman (1997),

resulta irónico destacar que en muchos casos [el] derecho [al] uso de su territorio tradicional [...] fue parcialmente reconocido y respetado bajo el régimen colonial por medio de los títulos virreinales. A pesar de que éste fuera un orden político que no tenía nada que ver con la democracia y que dichos títulos reconocieran una fracción ínfima del territorio compartido por los wixáritari y otros pueblos antes de la invasión española, los derechos reconocidos durante la colonia y consagrados por las autoridades tradicionales wixáritari en sus discursos míticos sobre las mojoneras limítrofas hoy en día constituyen la base para las reclamaciones territoriales más extensas. (ver también Neurath y Pacheco s/d: 38).

Con las Leyes de Reforma dio inicio un gran problema para los huicholes y demás indígenas de México en la conservación de su territorio por la ley de manos muertas decretada el 25 de junio de 1856, en la cual se consideraba "que uno de los mayores obstáculos para la prosperidad y engrandecimiento de la nación es la falta de movimiento (sic) libre circulación de una gran parte de la propiedad raíz, base fundamental de la riqueza pública" (Ley de Desamortización de Bienes de Manos Muertas). Por tal motivo, decía esta ley en su artículo 5: "Tanto las (fincas) urbanas como las rústicas que no estén arrendadas a la fecha de la publicación de esta ley, se adjudicarán al mejor postor en almoneda que se celebrará ante la primera autoridad política del Partido." Los indígenas, igualados en teoría por los liberales con los demás mexicanos del país, en la práctica estaban en desigualdad económica, política y educativa ante las élites locales y federales. Comenzaron a perder tierras ante el mayor conocimiento y sobre todo mayor poder económico-político de algunos mestizos. Al considerarse como tierras ociosas aquellas que los pudientes demostraran en tal estado, podían ser cedidas a ellos de acuerdo con la ley y mediante el pago correspondiente para su "debida" explotación. Además de lo legal, los mestizos con poder también comenzaron a invadir las tierras de los indígenas teniendo que demostrar los segundos, sin poder hacerlo en muchos de los casos, la posesión de aquello que les estaban quitando.

Según Meyer en el caso del séptimo cantón de Jalisco, actual estado de Nayarit, la amortización de bienes no afectó en medida importante al territorio de los pueblos indígenas por aquel tiempo (Meyer, 1983: 5-30). Sin embargo no se puede decir lo mismo para todo el Jalisco decimonónico porque pueblos como Tenzompan y Colotlán, en un proceso que inició con la vigorosa actividad minera del los siglos XVIII y XIX en sus territorios 
(ver Brading 1969; Ruiz 2014) poco a poco pasaron de ser pueblos indígenas huicholes a pueblos mestizos. Por esto último, y por el hecho de que hacia 1852 los padres franciscanos hicieron gran destrucción de templos y efigies de dioses wixaritari (Rojas 1992: 169-171), no resulta extraño que al levantarse en armas el posteriormente mítico y ambivalente Manuel Lozada,7 muchos integrantes del grupo huichol al lado de coras y tepehuanos lo siguieran, logrando con esa revuelta frenar un poco las acciones para desplazarlos, aunque fuera sólo por un tiempo, porque Manuel Lozada fue derrotado cerca de Guadalajara por el ejército a mando de Ramón Corona, y murió fusilado en 1873.

En 1883, con el afianzamiento de Porfirio Díaz en la presidencia de México, se promulgó la Ley de terrenos baldíos mediante la cual se buscaba que extranjeros deseables colonizaran el territorio mexicano, para ello se crearon las compañías deslindadoras a las que por su trabajo se les cedería la tercera parte del terreno que deslindaran. En 1894 la situación empeoró al reformar la ley y quitar muchas de las limitantes para apoderarse de tierras. Comenta Torres Conteras que

se ignora si los deslindes llegaron realmente a tierras huicholas. Aunque al parecer nunca se dio solución al problema porque cuando Lumholtz hizo su recorrido, los huicholes le pidieron que les ayudara a escribir sus peticiones para mandarlas al gobierno de Díaz (Torres 2000: 51).

Neurath y Pacheco por su parte, afirman:

el Porfiriato fue una época difícil para los huicholes porque las compañías deslindadoras acosaron los territorios indígenas de la sierra con el propósito de expropiar las supuestas tierras baldías y venderlas a los grandes latifundistas, entonces en plena expansión. Efectivamente, las comunidades del extremo nororiental (Tenzompa y La Soledad) fueron despojadas de sus tierras, y muy pronto perdieron su identidad indígena (Neurath y Pacheco s/d: 38).

Fuera por la ley porfiriana, las versiones reformadas de la misma, o el poder económico y político de ciertos grupos o individuos, lo que podemos decir con certeza es que los wixaritari tenían problemas por tierras con gente teiwari cuando Lumholtz llegó a su territorio.

\section{LOS WIXARITARI COMO TRIBU DE ARTISTAS. EXTRANJEROS POR TERRITORIO WIXARIKA A FINALES DEL SIGLO XIX Y PRIMERA MITAD DEL SIGLO XX.}

En el pleno apogeo de la pax porfiriana, en 1895, Carl Lumholtz llegó al territorio wixarika, luego de atravesar el norte de México buscando encontrar rastros de los descendientes de "los antiguos indios Pueblo que habían construido edificaciones monumentales en las cuevas del suroeste de los Estados Unidos" (Romo 2002: 332) Pero al parecer también tenía un objetivo tan importante como aquel: estudiar la cultura de los huicholes, como confiesa en El México desconocido al serle informado por un

agente de la autoridad mexicana de Jesús María que los huicholes se habían levantado en armas y estaban resueltos a no dejarme entrar en sus pueblos [...] Los arrieros dejaron de cargar y propusieron que nos volviésemos, alegando que los huicholes a más de ser malos y asesinos, eran muchos y nos matarían a todos. 
¿Qué iba yo a hacer? Desistirme de visitar una tribu cuyo estudio constituía mi propósito principal; no había ni qué pensarlo (Lumholtz 1904 : 515 TI).

De los grupos indígenas que visitó, "poco más se sabía que sus nombres" (Lumholtz, Prefacio xvi) entre los no indígenas. $Y$ narra que, en términos generales, "salvo ciertos especialistas distinguidos, aún los mexicanos inteligentes saben muy poco de las costumbres, y mucho menos de las creencias de los aborígenes" (Lumholtz 1904: 196). Al respecto podemos leer lo expresado por el gobernador de Jalisco de aquella época cuando el investigador noruego le externó su deseo por convivir con "grupos primitivos":

En un extremo de este mismo estado, encontrará indígenas totalmente salvajes que llevan el pelo largo y rehúsan pagar impuestos. De cuando en cuando vienen a Guadalajara a verme y duermen en el patio del palacio, que, al parecer, lo consideran su propia casa. (Lumholtz 1986: 11)

De hecho, y pese a los resultados de sus investigaciones entre los wixaritari el mismo Lumholtz parece compartir esa visión dado que en repetidas ocasiones habla de los huicholes como salvajes y primitivos. Y todavía la refuerza al escribir que cuando los conoció, se encontraban "en el mismo estado de barbarie que cuando Cortés llegó a México" (Lumholtz 1986: 29). ${ }^{8}$

En ese orden de ideas, para el investigador noruego la cultura huichola era producto de un desarrollo libre o casi libre de influencia externa, explicado, desde su punto de vista, por las condiciones de aislamiento en que se encontraba la región huichola. Así, la introducción de la chaquira en la ornamentación y el mundo simbólico huichol; el paño de fabricación teiwari; el ganado vacuno tanto en la vida secular como religiosa; la cría de ovejas y el uso de la lana; la aparición del eslabón de hierro español entre los wixaritari en su vida cotidiana, en los diseños de los tejidos y en lo religioso por su relación con el Abuelo Fuego; los instrumentos musicales inspirados en los europeos y usados en distintos ámbitos de la vida; la manta; agujas; algunos aspectos de la mitología cristiana; entre otros elementos; aunque percibidos, no obstarán para su tesis de que los huicholes son una etnia desarrollada endógenamente.

Bajo la importante influencia de las teorías evolucionistas, Lumholtz se lamentaba de la inminente desaparición de los indígenas ante el continuo contacto con "la civilización" porque veía en la cultura de aquellos, elementos muy importantes para la humanidad (Lumholtz 1904: 451-471 TII). Maravillado por la riqueza cultural que encontró, al mismo tiempo que por la necesidad de exponer objetos para quienes lo apoyaron económicamente en sus expediciones, realizó una impresionante colección de objetos. Para ello se valió de distintas estrategias, una de ellas, la compra de objetos que en algunos casos fueron elaborados a su gusto, es decir, de acuerdo a habilidades artísticas wixaritari que pudieran coincidir con la estética teiwari (ver Lumholtz 1986: 92, 95, 102 y $103,132,173$ y 174,233 y 234,236 y 237). Ante el inmenso conjunto de elementos que lo fascinaron al presentarse frente a sus sentidos, él será el primero que llame arte a la producción cultural de los huicholes. El arte de los huicholes para él, es la demostración del dominio de la técnica en la elaboración de los objetos y el complejo uso del símbolo en las representaciones huicholas. Aunado a lo anterior, es lógico pensar que Lumholtz es un 
predecesor importante en la fabricación de piezas de arte huichol con estética teiwari debido a sus peticiones de elaboración de objetos para su colección.

Casi por la misma época de la entrada de Lumholtz al territorio wixarika, llegó a esas tierras Leon Diguet, quien dejó constancia de su acercamiento a los huicholes en algunas descripciones de las costumbres de los miembros de ese grupo y un importante corpus de fotografías. Pero también coleccionó objetos producidos por los huicholes, y gracias a ello podemos darnos cuenta de que había distintas formas de trabajar la chaquira y que había diferencias en la producción entre unas comunidades y otras (Ver Diguet 1992). Además de lo anterior, este explorador francés se convirtió en el primer promotor de artistas huicholes en el extranjero del que hay noticia, según narra Olivia Kindl: "existió un primer intento de desarrollar el comercio del arte huichol desde 1898, cuando invitados por Diguet un matrimonio huichol se instaló en la calle de Washington en Paris para vender sus artesanías" (Kindl 2004: 129-155). ${ }^{9}$

Años más tarde, en 1905, arribó a lo que es el actual territorio del Gran Nayar el alemán Konrad Theodor Preuss, quien trabajó especialmente sobre la literatura, rituales y costumbres de los grupos indígenas del Gran Nayar y otros territorios de México, incluyendo los huicholes. Al igual que sus antecesores, hizo una considerable colección de objetos e historias sagradas wixaritari, de la cual podemos abrevar.

Luego de los trabajos de Lumholtz, Diguet y Preuss, parece que los huicholes no fueron sujetos de mucha atención para la sociedad teiwari y poco se conoce acerca de ellos antes de la Revolución de la cual queriendo o no formaron parte.

Al llegar la Revolución, aunque algunos de los wixaritari se pusieron de parte de Villa yéndose con sus fuerzas a su paso rumbo a la ciudad de México, cuando los vecinos mestizos se declararon a favor de Villa, los huicholes, comandados por el General Mezquite optaron por Venustiano Carranza logrando ganar varias batallas (Weigand 1992: 153-174). Y Aprovechando el movimiento, se deshicieron de los invasores de sus tierras por medio de la fuerza matando a unos y haciendo correr a otros, lo que les permitió recuperar algunas partes del territorio que les habían arrebatado. Por ejemplo, Santa Catarina, que era hacienda, dejó de serlo. Los huicholes recuerdan a ese periodo "como una época dorada -un tiempo sin vecinos, sin sacerdotes, durante el cual el maíz crecía grande y las cosechas eran buenas (y no estaban gravadas), y las ceremonias nativas florecían y se podían practicar sin la censura de los católicos (Weigand 1992: 121-130).

Pero como apunta el mismo investigador,

después de la derrota de Villa, los vencedores no hicieron mucho por entrar directamente o por controlar la zona de las montañas; más bien le dieron luz verde a sus bien armados aliados regionales para que intentaran recolonizar el área. Lo que conllevó el regreso de los mestizos a la zona huichola [...]. La comunidad que padeció la mayor presión fue la más grande, la más rica y la más conservadora: San Sebastián. Los ganaderos y los colonos vecinos, vencedores regionales de la Revolución, empezaron con un cuidadoso pero determinado regreso (Weigand 1992: 121-130).

En la Guerra Cristera los wixaritari estuvieron divididos en distintos bandos. “De los tres pueblos huicholes, 
teniendo por jefe a Juan Bautista. El segundo fue callista, debido a la influencia que en él ejercía el pueblo de Mezquitic antes de ser dominado por el Ejército Libertador. El último, San Andrés, permaneció totalmente neutral" (Weigand 1992: 121-130).

Hacia 1935 Bautista fue asesinado por unos huicholes pagados por los mestizos. Ya sin esa figura que los detuviera

[l]os ganaderos rurales perseguían y muchas veces asesinaban a los huicholes, cristeros o no, indiscriminadamente y, además, también mataban a las mujeres y a los niños. Su meta era invadir la comunidad y usar sus pastos exclusivamente para beneficio propio.

En una diáspora, miles de huicholes huyeron del caos que se extendió a las áreas que en un principio habían permanecido neutrales o a favor del gobierno, como Tuxpan, Santa Catarina y San Andrés (aunque con menor fuerza). Los refugiados se fueron a los pueblos regionales, a las ciudades, a la costa, y con los coras al nuevo estado de Nayarit. (Weigand 1992: 121-130).

La Cristiada trajo nuevos cambios en la configuración poblacional y territorial de los huicholes. Muchos se fueron a vivir fuera del territorio donde habían nacido y se establecieron en otras partes. Un número importante se fue al estado de Nayarit. ${ }^{10}$ San Sebastián, como ya se comentaba, fue la comunidad que más sufrió pérdidas luego de la Cristiada, parte de sus tierras fueron apropiadas por mestizos y en 1951 hasta se estableció un ejido, Los Amoles. Años más tarde, de la mano de Pedro de Haro, un personaje hijo de teiwarixi pero que adoptó la identidad wixarika, los wixaritari comenzaron a recuperar parte de sus tierras. (ver al respecto Benítez 1968)

En la década de 1930 tocó el turno a Robert M. Zingg de hacer investigación entre los huicholes apoyándose, como él lo reconoce, en los datos de sus predecesores, Lumholtz y Preuss (Zingg, 1982; Zingg 1998). Para este trabajo, cabe destacar que sus descripciones atestiguan la influencia de los teiwarixi en la cultura wixarika, aunque a lo largo de su obra más bien se encarga de aducir lo contrario, siguiendo la tesis de Lumholtz.

Para Zingg, siguiendo a Sapir, los huicholes pertenecen a las "culturas primitivas" y son parte de las "culturas genuinas", que a diferencia de las clasificadas por él como "espurias", permiten a sus integrantes desarrollar su potencial humano. Así, respecto a la religión expresa: “Infinitamente más encantadora que la creación religiosa de los polinesios, la religión huichol incuestionablemente produce felicidad a todo el grupo" (Zingg 1982 vol. 2: 520). Si relacionamos esto con la búsqueda de los admiradores de grupos humanos "auténticos" y en contacto íntimo con la naturaleza y la búsqueda de ser uno con el universo, el investigador norteamericano podría apuntalar el acercamiento en esa dirección hacia los wixaritari. Más aún cuando abunda, “[s]i yo hubiera podido elegir entre nacer huichol o norteamericano, habría preferido lo primero, aunque pocas son las culturas primitivas que escogería." (Zingg 1982 vol 2: 520) En el mismo sentido, el título de uno de sus trabajos, The Huichols: primitive artists, pudiera resumir una de las maneras en que el huichol es pensado por muchos no huicholes. Es decir, no un pueblo de indígenas que combinan la agricultura en sus tierras con una migración anual a los campos agrícolas de otras latitudes para obtener ingresos que les permitan sobrevivir, tampoco un grupo humano que vive de acuerdo a la época apropiándose de aquellos elementos teiwarixi que considera de utilidad; sino más 
bien como un grupo de seres humanos primitivos que siempre visten un hermoso traje multicolor, que se dedican a crear piezas artísticas y que viven en armonía con la naturaleza

A manera de hipótesis, se puede considerar que el paso de Lumholtz, Diguet, Preuss y Zingg los wixaritari tuvo influencia en el arte huichol: es posible que la experiencia de fabricar ciertos objetos para teiwarixi, mostrara a algunos huicholes que podían producir un tipo de artefactos para vender sin correr el peligro de hacer enojar a los ancestros, pues lo producido para tal fin no era la ofrenda para los ancestros ni constituía reproducción de deidades. Guardando la debida distancia entre los wixaritari de fines del siglo XIX, retomamos una que Neurath (2005) provee sobre cómo evitan los peligros los artistas wixaritari actuales

Una estrategia para evitar significados religiosos es la combinación aleatoria de los íconos. En el arte ritual, emblemas como águila, venado, peyote y maíz corresponden a un programa iconográfico coherente. En la artesanía, se usan los mismos motivos, pero éstos se acomodan de una forma arbitraria [...] Cuando mucho, se improvisan unos "mitos" que vinculan los diferentes elementos icónicos con base en asociaciones libres. Además, como lo ha señalado Kindl (2003) para el caso de las jícaras artesanales, muchas veces, se introducen simetrías distintas, hexagonales, que no corresponden a un referente cosmológico, como en el caso de los quincunces que predominan en el arte ritual (Neurath 2005: 43).

Se debe reconocer, sin embargo, que la ni la hipótesis planteada ni la explicación de Neurath dejan clara la aparición del arte huichol como objeto comercializable porque aún cuando no es la práctica general, en Haramaratsie - Casa de Haramara, en San Blas, Nayarit -he visto piezas de las que se venden como arte huichol, depositadas como ofrenda a Haramara, la deidad del mar. Además, para algunos huicholes, aunque realmente minoría, vender piezas con imágenes de los símbolos wixaritari sea cual sea la combinación, es al menos "una payasada" cuando no un auténtico peligro porque las deidades pueden enojarse al ser copiadas en las piezas.

Ahora bien, pese al interés mostrado por Zingg y los estudiosos anteriores a él por la cultura wixarika, los huicholes sólo saltarán de forma importante a la escena nacional e internacional por su arte y religión hasta después de la segunda mitad del siglo XX, gracias a una serie de sucesos de índole diversa que llevaron a personas de variadas culturas y sociedades a una valoración positiva de algunas facetas de lo wixarika, comenzando con la labor del organismo oficial que se encargaría de intentar arreglar lo que se llamó el "problema indígena", el Instituto Nacional Indigenista (INI).

\section{EL “REDESCUBRIMIENTO" DE LOS WIXARITARI COMO “TRIBU DE ARTISTAS" POR EL ESTADO MEXICANO A LA SEGUNDA MITAD DEL SIGLO XX}

Luego de la Revolución, lo que se necesitaba en México, para muchos intelectuales de la época, era forjar patria e hicieron suyos los pensamientos de Manuel Gamio, uno de los grandes precursores del indigenismo clásico mexicano y mundial. Para Gamio (1916), la "fusión de razas, convergencia y fusión de manifestaciones culturales, unificación lingüística y equilibrio económico de los elementos sociales" eran necesarios para que se tuviera una patria fuerte y con una nacionalidad definida. Aunque sus ideas también estaban matizadas debido a su admiración por algunos aspectos de los indígenas, especialmente el arte (Gamio, AHSEP, Fondo SEP, Caja 6/9:24). Además, 
para hacer justicia a Gamio hay que considerar que en la época de la aparición de Forjando Patria, había un México en ebullición con distintos sectores buscando el poder y que, además, en el pensamiento de este antropólogo, alumno de Boas, estaban presentes las condiciones de vida de los indígenas y el racismo recalcitrante contra los indios por parte de la sociedad mestiza, situaciones a las que pretendía dar solución por medio del mestizaje. En el mismo sentido, Vasconcelos (1925) propugnaba por una fusión de razas de la que surgiría la "raza cósmica. Bassols por su parte, en 1931 se pronunciaba por la integración del indio, quisiera o no quisiera:

Si queremos realmente incorporar al indígena a la civilización occidental, debemos reconocer que puede haber, y de hecho hay, un momento determinado en el que se contraponen el interés económico del campesino y el mantenimiento de formas de vida industrial y artística llenas de color, pero contrarias a los intereses de los campesinos (Aguirre 1973: 20).

En esa lógica de ideas nació el INI en 1948, y bajo la dirección de Alfonso Caso asumió los ideales de un nacionalismo que buscaba forjar patria moderna, poniendo en acción una antropología práctica, que sirviera como instrumento eficaz de los “ideales de la revolución” según el discurso de la élite política: un país nuevo con una población mexicana poseedora de una cultura única e "imaginada" (Bonfil 1987). Así lo explicaba Caso y Andrade:

Frente a una cultura como la nuestra, inspirada fundamentalmente en el uso adecuado de una tecnología que constantemente se transforma por los descubrimientos científicos; [...] existen grupos atrasados que forman comunidades a las que hay que ayudar para lograr su transformación en los aspectos económico, higiénico, educativo y político; es decir, en una palabra, la transformación de su cultura. (Caso y Andrade 1980: 60-70)

Para ello, proponían la aculturación dirigida como medio de integrar al indígena a la sociedad nacional cambiando sus aspectos "arcaicos, deficientes, - y en muchos casos nocivos de esa cultura - en aspectos más útiles para la vida del individuo y de la comunidad" (Caso y Andrade 1958: 35). Es decir, convertir al indígena en mexicano mestizo. Con ese fin, en la década de 1950 se crearon los Centros Coordinadores Indigenistas (CCls), campos experimentales de la nueva antropología mexicana y a través del tiempo forjadores de indios nuevos, a pesar de que la tarea fue más bien convertir a los indígenas en nuevos mexicanos. Los CCls eran pues la esperanza para desaparecer el llamado "problema indígena". Caso así lo vaticinaba en una conferencia en el Instituto de Altos Estudios de América Latina, en la Universidad de París, el 20 de octubre de 1956: "De este modo esperamos que el problema indígena como tal desaparezca en los próximos 20 años. Pero eso no implica naturalmente que los valores culturales indígenas habrán muerto entonces; por el contrario, seguirán incorporándose, como ha sucedido hasta hoy, en la vida mexicana" (Montemayor s/d) Es decir, en el problema también veía algunos aspectos positivos como las piezas artísticas que creaban algunos grupos, catalogadas como "arte popular". Por ello hacia 1948 expresaba el fundador del INI:

[q]uedan, dentro de estas comunidades indígenas, aspectos nobles de sus viejas culturas, perfiles que harán más rico el ambiente cultural de nuestros pueblos, elementos que debemos salvar de la total destrucción, si queremos ser hombres conscientes y atentos al desarrollo de nuestros pueblos. (Caso y Andrade 1948). 
Mas, el arte popular que funcionara en un medio comercial no podía ser todas "las manifestaciones estéticas que sean un producto espontáneo de la vida cultural del pueblo mexicano", había que escoger lo "mejor" de los elementos que componían tales manifestaciones para apoyar su conservación y se buscaría desaparecer lo que era "negativo" (Caso y Andrade 1971: 229). Quizás eso fue lo que hizo Soto Soria.

Fuera por buscar lo positivo de los grupos indígenas, lo bello de sus creaciones, el nacionalismo, la economía, o la combinación de los cuatro factores, a principios de la década de 1950, el museógrafo Alfonso Soto Soria fue contratado por el gobierno de México para desarrollar el primer proyecto del Museo Nacional de Artes e Industrias Populares (MNAIP) cuya culminación sería la exposición denominada “Los huicholes y sus vecinos del norte". Narra Soto Soria que del grupo huichol se sabía muy poco a nivel nacional. En su caso, sabía de ellos por El México Desconocido de Carl Lumholtz y "otros trabajos de un Antropólogo Zings [sic] que había entrado también un poco por la zona" (Vázquez Olvera 2005: 137), pero nada más.

Soto Soria se adentró al territorio huichol en compañía de Alfonso Villa Rojas, quien iba comisionado por el INI para buscar el lugar ideal dónde instalar el Centro Coordinador Cora Huichol. El programa a cumplir era largo pues "consistía en visitar a los huicholes, los coras, los tepehuanes, los tarahuaras, los yaquis, los mayos, los ópatas, los pimas, los pápagos, los kikapúes, a todos los grupos del norte de la república..." (Vázquez Olvera 2005: 137). Sin embargo, el museógrafo sólo visitó los primeros cinco debido a que lo encontrado entre los huicholes lo había convencido de no buscar más: “Descubrimos que era inútil, o más bien, que no era razonable seguir visitando grupos que no iban a estar incorporados a la exposición por la riqueza material que tenía el grupo huichol" (Vázquez Olvera 2005: 142). Aunado a lo anterior, entre los otros grupos visitados los yaquis no querían tratar con los yoris (los blancos), y lo más importante, los demás estaban, dice el museógrafo, "más mestizados en cuanto a los elementos materiales de la cultura y no ofrecían muchas posibilidades de exhibición, puesto que lo más importante de su tradición son las fiestas, las danzas" (Vázquez Olvera 2005: 143). El representante del Estado se erigió así en árbitro de lo auténtico, lo puro, lo tradicional y lo que era arte y no arte.

De este modo, para 1954 Soto Soria organizó la primera exposición de arte huichol en el MNAIP en la ciudad de México con exitoso resultado. Poco después montaría otra en el Ayuntamiento de Guadalajara, por encargo de Agustín Yáñez, gobernador de Jalisco, quien había otorgado el premio Jalisco en el rubro de arte a los huicholes en 1955 y necesitaba justificar el premio ante la sociedad jalisciense.

La exposición que hicimos de los huicholes y las investigaciones que se hicieron con motivo de esta exposición pusieron de moda a los huicholes en Guadalajara, al grado que el gobernador , el licenciado Yáñez, decidió que el premio de arte de un año se entregara a los huicholes por su producción artesanal.; para justificar esta decisión, porque era un premio que normalmente se daba en el área de artes plásticas a pintores o escultores, pidió que le organizáramos una gran exposición de arte huichol ya no con el concepto de artesanías sino de arte (Vázquez Olvera 2005: 156)

Para que la exposición se realizara "ya no con el concepto de artesanía sino de arte" Soto Soria introdujo algunas modificaciones a los materiales utilizados por aquella época según narra él mismo: “Me fui a la sierra 
y les llevé todo el material que necesitaban: estambres, cera de Campeche y tablas; pero para que fueran auténticas tablas conseguí una de tres cuartos de pulgada de grueso, para que sintiera que era madera de árbol, no industrializado" (Vázquez Olvera 2005: 156) Asimismo se buscó "ambientar la presencia de las tradiciones" mediante utilería, indumentaria y fotografías, las cuáles se consiguieron por medio del convencimiento y el uso del poder conferido al representante del supremo gobierno (Vázquez Olvera 2005: 140-146). De esa manera, se logró la exposición inédita de 250 "tablillas" o cuadros huicholes (Peñaloza 2001). Cabe decir que Soto Soria introdujo uniformidad en cuanto a medidas de esas obras de arte producidas por los huicholes y cambio en algunos de los materiales. En cuanto al papel del museólogo en la manufactura de nuevos objetos dentro del arte huichol, Acelia García narra:

en 1965 [visité] el Museo de Antropología e Historia de la Ciudad de México, donde la colección formada por el etnólogo Soto Soria mostraba bolsas de noche de chaquira. La sorpresa fue al llegar a las comunidades donde no existían, lo que sugiere una promoción de arte del etnólogo, quien al parecer pidió a los huicholes que hicieran tres brazaletes para así obtener el formato necesario [...] Soto Soria pidió a los huicholes toda una colección para el Museo motivándolos con diseños de punto de cruz de libros europeos y otras publicaciones. (Durán 2008).

Junto a lo encomendado a Soto Soria, el INI pronto se involucró en el desarrollo del arte huichol como actividad comercial. Para 1957 ya estaba otorgando un crédito sin réditos por 5000 pesos a un grupo de huicholes de Santa Catarina "destinados al impulso de sus hilados, tejidos y bordados" (Fabila 1959: 66). De la misma forma, comenzó a apoyar muy temprano su difusión por medio de ferias en distintos estados del país. Además, con el establecimiento del llamado Plan Lerma a partir de 1965 y de la Coordinación HUICOT ${ }^{11}$ en 1971 se buscó involucrar a otras instituciones gubernamentales para la venta y fomento de las artesanías huicholas, tal fue el caso de CONASUPO, institución con la que el INI firmó un convenio en 1968 para que a través de su red de tiendas se hicieran llegar los materiales para la manufactura de las artesanías y recolectar la producción para introducirla en el mercado nacional (Hernández 1971: 130). Asimismo, las Casas de las Artesanías de Jalisco y Nayarit, el Banco Nacional de Fomento al Comercio (BANFOCO), el MNAIP y el FONART, junto con "algunos particulares de los estados de Durango, Jalisco, Nayarit y Zacatecas" (Centro Coordinador para el Desarrollo de la Región Huicot 1971: 122) fueron los principales encargados de convertir en éxito económico el fenómeno de la artesanía huichola. No obstante, la labor del INI impactará en mayor medida hasta mucho tiempo después de esas primeras acciones en combinación con otros factores como la apertura de carreteras y pistas de aterrizaje en el territorio huichol que allanaron el camino para la entrada y salida cada vez mayor de personas y bienes de intercambio. Además, las escuelas y los "agentes de cambio" emanados de ellas también han sido parte muy importante del cambio cultural entre los huicholes. Pese a que por cuestión de espacio no se tocará en este artículo, aunado a esos factores, en la década de 1960 aparece el movimiento hippie y de la mano de la moda psicodélica, la búsqueda de espiritualidades auténticas y publicaciones como Myth and art de Peter Furst (1968), entre otros factores, surge ahora sí la venta de un arte huichol producido específicamente para el mundo del intercambio comercial, especialmente para el comprador norteamericano, pero al que se sumaron gente de 
muchos países, incluyendo México. De esa forma, la imagen del Wixarika se fijó todavía más en el imaginario teiwari como la de "una tribu de artistas.

\section{CONCLUSIONES}

Los "xurutes, uzares o vizuritas", nombres dados a los ancestros más directos de los actuales wixaritari, imaginados como antropófagos exóticos y salvajes a la llegada de los misioneros españoles y novohispanos, poco a poco van cambiando a indios fronterizos y luego a flecheros aliados de los españoles en la conquista del Gran Nayar. Gracias a esa alianza conservaron parte importante de su territorio y algunas de sus costumbres fueron relativamente toleradas, dado que en lo religioso, los huicholes no abandonaron muchas de las prácticas aconsejadas por el demonio según el punto de vista de los misioneros católicos. Y en cuanto a lo salvaje, ni siquiera habían cambiado en el imaginario teiwari a la llegada de Lumholtz a finales del siglo XIX pues según el gobernador de Jalisco, los huicholes eran "indígenas totalmente salvajes que llevan el pelo largo y rehúsan pagar impuestos", opinión que compartirá el noruego al indicar en su obra que los huicholes se encontraban "en el mismo estado de barbarie que cuando Cortés llegó a México". Sin embargo, como lo establece Celia García de Weigand, desde los primeros años de conquista los antepasados de los actuales wixaritari ya habían incorporado varios elementos de la cultura española a su propia cultura, entre ellos materiales como chaquira y lana, que concordando con Liffman (comentario personal), "fueron sustitutos funcionales para cosas que ya tenían: abalorios de concha o piedras semipreciosas y ixtle o algodón aunque curiosamente la palabra por éste es "lana terrestre" (kwiemuxa)".

Hay pues una base de prácticas culturales tradicionales de siglos en la cultura wixarika que se ha transformado e incorporado elementos otrora teiwari y ahora firmemente arraigados en el hacer y el saber huichol. De manera contraria al aislamiento planteado por investigadores como Lumholtz, Zingg, Soto Soria, Benítez, Furst, Reed, Myerhoff, y Berrin, entre otros, la cultura de los wixaritari se ha desarrollado en la interacción con otras culturas. La conservación, transformación y abandono de algunos aspectos de sus prácticas culturales, tradiciones y costumbres han sido producto tanto del contacto de los antepasados de los wixaritari con grupos indígenas del Gran Nayar y el desarrollo de características culturales muy propias, como también de los contactos interculturales de los actuales miembros de la etnia wixarika y lo heredado de los ancestros. Es decir, los wixaritari han compartido rasgos culturales con otros grupos indígenas como el culto del peyote, la mitología, el calendario del ciclo anual agrícola, conocimientos astronómicos, utensilios, desde tiempos prehispánicos. Desde la llegada de los europeos, también cambiaron su cultura por su relación con ellos y con los indígenas del centro castellanizados en ciertos aspectos, junto con los negros traídos como esclavos y los mestizos mexicanos; y de algunos años hacia acá [...] los estadounidenses y gente de distintas nacionalidades. La construcción de la actual cultura wixarika es entonces el producto de la interacción cultural y de lucha constante del wixarika con sus "Otros" históricos en la que elementos inalienables como su autonomía han sido negociados para poder conservarlos (Ver Weigand 1978: 101-115). Así es como debemos entender a tal grupo y a prácticas actuales 
que desconociendo el proceso histórico nos pudieran parecer como algo que se realiza ahora por primera vez o como algo que se realiza desde el principio de los tiempos.

Se debe reconocer que, por cuestión de espacio, se queda a deber la lucha por el territorio huichol de la última época descrita y la de esos tiempos hasta los actuales. ${ }^{12}$ Asimismo, hace falta en el artículo la descripción y análisis de las importantes transformaciones que el arte huichol ha tenido desde la época posterior a Soto Soria, especialmente lo relacionado con el movimiento hippie, nueva era y mexicanidad, que es la forma de arte huichol que más se conoce. Sin embargo, introducir estos temas en el presente artículo contribuiría a una descripción y análisis todavía menores a lo realizado. ${ }^{13}$ 


\section{NOTAS}

1. El estudio de la cultura wixarika y el arte huichol son vetas tan grandes que se pueden establecer discusiones desde distintas fronteras. Así, establecer una discusión con Primitive art de Sally Price podría traer a la luz algunos elementos sobre el porqué del consumo del arte huichol a la vez que explicaría, aunque de forma parcial las razones por las cuales hay artes indígenas para consumo "artístico" y otras para consumo suntuoso", entre muchas relaciones que se pueden establecer; se la misma forma, iniciar una discusión sobre arte huichol desde perspectivas teóricas de la antropología del arte, iniciando por Boas (1947 [1927]) y siguiendo con autores como Negrín (2005) o en términos más generales con Lagrou (2010) y las paradojas de llamar arte a lo que en ciertos términos del aura benjaminiana podría no ser arte, sería una muy importante discusión en términos de intentar definir lo que es un arte como el huichol; o en el mismo sentido acercarnos al arte huichol, desde la reflexividad, considerando por ejemplo a Araiza et al (2013) podría acercarnos a una comprensión socio-antropológica del fenómeno; sin embargo, pese a lo enriquecedor que sería establecer el diálogo entre el arte huichol y esos campos del conocimiento, ello no forma parte del objetivo del presente escrito, dado el no tan ambicioso objetivo señalado en la introducción.

2. Un reconocimiento y definición más amplios del arte producido por grupos indígenas se encuentra en Boas (1947 [1927]).

3. Además de lo anterior, también se deben considerar para un análisis de la composición de los grupos indígenas del Gran Nayar dos documentos citados en Neurath y Pacheco (s/f: 41-42): el Mapa del Obispado de Compostela o Pintura del Nuevo Reino de Galicia (Castro 1996: 62), fechado como anterior al periodo entre 1542 y 1546 (Weigand y García 1996: 57), señala dos asentamientos grandes de indios en el Gran Nayar: Cora (probablemente La Mesa del Nayar) y Guaynamota. Al norte del Río Santiago y al oriente de Cora, se dibujan vagamente los territorios de los xuructequanes o xuructequales, así como de los tequales. Más al norte se ubican los tepeguanes y tenamaztle. Los xuructecuales oxuructequanes probablemente son hablantes del idioma wixarika. El Mapa de Abraham Ortelius, Hispaniae Novae Sivae Magnae, Recens et Vera Descriptio (León-Portilla 1995: 63), que forma parte de su Theatrum Orbis Terrarum y que data de 1579, menciona 'xurute prouincia'."

4. Marina Anguiano (1974) escribe que "sólo en el siglo XVIII aparece el término usado actualmente con ciertas variaciones en su escritura: güichol, huitzol y guisol. Cfr. Velázquez, 1961, pp- 75, 47, 51". Sin embargo, hacia 1652 Pedro Lucas Marín informó al Obispo Juan Ruiz Colmenero de dos testigos que hablaron de la existencia de la lengua guichola y otro sobre la presencia de los guisoles en el Nayarit. Hacia 1672 Arias de Saavedra ya hablaba de Xamucas o Huitzoles como una de las seis naciones que componían las doctrinas de la sierra. (Arias y Saavedra Antonio, en Santoscoy 1899: 28).

5. La primera de la que se tiene registro es la travesía emprendida por Pere Almendes Chirinos, enviado por Nuño de Guzmán para descubrir nuevas rutas a Tepic hacia 1530, quien iniciando en Tlatelnango atravesó por "lo que serían después Huazamota, Huaynamota, Xora, Xala y Ahuacatlán." (Rojas 1993: 26).

6. Sobre el apoyo brindado por los indios flecheros a los españoles en la salvaguarda de las fronteras y en la conquista de otros grupos indígenas, ver Güereca (2013: pp. 90-124).

7. "El tigre de álica representa para los vecinos de la Mesa del Nayar un asesino que no tenía compasión con mujeres ni con niños. En cambio el legendario Manuel Lozada puede interpretarse como la versión de Santiago Apóstol, mezcla además de héroe cultural y bandido generoso; se dice entre otras cosas que nació en la Mesa, que se comunicana con "los dioses", obteniendo así sabiduría y fuerza sobre humanas; se dice también que luchó contra los soldados conquistadores y que los venció mucha veces solamente provisto con un machete" (Vázquez 1987: 101-102).

8. Fernando Benítez (1968), a su vez, afirma que "no hay diferencias apreciables entre los huicholes fijados por Lumholtz y los que están en San Andrés.

9. Beatriz Rojas narra también este hecho aunque diferente en el número de personas. Ella apunta: “Diguet culminó su aventura en la sierra llevándose dos parejas de huicholes a vivir a Paris, donde las instaló dignamente, poniéndoles un maestro de francés y propiciando que siguieran fabricando sus artesanías" (Rojas 1993: 153).

10. Zing (1982; 133) comenta respecto a los huicholes de Tuxpan: "Ios indios abandonaron la sierra y se fueron a vivir con los mexicanos a la barranca de Bolaños [donde] trabajaban como peones en agricultura y en el cuidado de rebaños. En la costa de Nayarit había otras colonias de huicholes exiliados voluntariamente de la sierra debido a las atrocidades cometidas contra ellos por los grupos en pugna.". 
11. Se le llamó HUICOT para denominar la región de las etnias huichol, cora y tepehuano.

12. Para obtener un panorama mayor sobre ese tema leer Benítez (1968, vol II), Weigand (1992), Torres (2000), Neurath (2002), Liffman (2005 y 2012).

13. El movimiento hippie y otros movimientos analizados como transformadores de la imagen del wixarika en el imaginario teiwari son considerados en otro artículo, actualmente en prensa, titulado "La transformación del arte huichol en la Nueva Era" 


\section{REFERÊNCIAS BIBLIOGRÁFICAS}

AGUIRRE BELTRÁN, Gonzalo. 1973. Teoría y Práctica de la Educación Indígena. Colección SEP Setentas. México: Secretaría de Educación Pública.

ANGUIANO, Marina. 1974 "El cambio de varas entre los huicholes de San Andres Cohamiata, Jalisco". Anales de Antropología XI: $169-187$

ARAIZA, Elizabeth (ed.). 2013. Las artes del ritual. Nuevas propuestas para la antropología del arte desde el occidente de México. Zamora: El Colegio de Michoacán.

BEIMBORN, María Florentine; ROMANDÍA PEÑAFLOR, Alberto. 2009. “Emigración y continuidad cultural de los wixaritari. Breve reflexión sobre una relación ambigua". LiminaR. Estudios Sociales y Humanísticos 7 (2): 13-29.

BENÍTEZ, Fernando. 1968. Los indios de México. Vol. II. México. Biblioteca Era Serie Mayor.

BERRIN, Kathleen (ed.). 1978. Art of the Huichol Indians. New York: The Fine Arts Museums of San Francisco/ Harry N. Abrams, Inc. Publishers.

BOAS, Franz. 1947 [1927]. El arte primitivo. México: Fondo de Cultura Económica.

BONFIL BATALLA, Guillermo. 1987. México profundo: una civilización negada. México: SEP/ CIESAS.

BRADING, David. 1969. “La minería de la plata en el siglo XVIII: el caso de Bolaños”. Historia Mexicana 18 (3), $317-333$.

CASO Y ANDRADE, Alfonso. 1948. “Definición del indio y lo indio”. América Indígena VIII (5): $239-247$.

1958. Indigenismo. México: Instituto Nacional Indigenista.

1971. La comunidad indígena. México: SEP/ Diana.

CENTRO COORDINADOR PARA EL DESARROLLO DE LA REGIÓN HUICOT. 1976. Informe 1976 del Centro Coordinador para el Desarrollo de la Región Huicot. Tepic: INI.

DE CIUDAD REAL, Antonio. 1976. Tratado curioso y docto de las grandezas de la Nueva España. Tomo II. México: UNAM.

DIGUET, Leon. 1992. Por tierras occidentales. Entre sierras y barrancas. (J. Jáuregui y J. Meyer, eds.). México: Centro de Estudios Mexicanos y Centroamericanos de la Embajada de Francia en México/ INI.

DURÁN, Cecilia. 2008. "Acelia García, 43 años de estudio del arte huichol de la chaquira”. La Jornada de Jalisco. 22 de junio.

FABILA, Alfonso. 1959. Los huicholes de Jalisco. México: Instituto Nacional Indigenista/ Gobierno del Estado de México/ Gobierno del Distrito Federal.

FRESÁN JIMÉNEZ, Mariana. 2002. Nierika. Una ventana al mundo de los antepasados. México: CONACULTA/ FONCA. FURST, Peter. "Myth in Art: a Huichol Depicts His Reality". The Quarterly 7(3):16-26.

FURST, Peter T; NAHMAD, Salomón. 1972. Mitos y arte huichol. México: Secretaría de Educación Pública. Colección SEP SETENTAS (50).

GARCÍA DE WEIGAND, Acelia. 2002. “Las tablas huicholas y su origen”. In: P. Weigand (comp.). Estudio histórico y cultural sobre los huicholes. México: Universidad de Guadalajara.

GERHARD, Peter. 1996. La frontera norte de la Nueva España. México: Universidad Nacional Autónoma de México. 
GÜERECA DURÁN, Rauel Eréndira. 2013. Las milicias de indios flecheros en la Nueva España, Siglos XVI-XVIII. Tesis de maestría, UNAM.

HERNANDEZ MORENO, Jorge. 1971. "Artesanía”. In: Acción Indigenista en la zona cora huichol. México: Instituto Nacional Indigenista.

KINDL, Olivia Selena. 2004. “El arte huichol contemporáneo”. In: P. López González et al. (org). Artes visuales de Nayarit y productos culturales. Tepic: INAH/ Gobierno del Estado de Nayarit/ CONACULTA.

LAGROU, Els. 2010. “Arte ou artefato? Agência e significado nas artes indígenas". En Revista Proa 01(02):1-26.

LÁZARO DE ARREGUI, Domingo. 1980. Descripción de la Nueva Galicia, estudio preliminar de Francois Chevalier. Guadalajara: Gobierno de Jalisco.

LEY DE DESAMORTIZACIÓN DE BIENES DE MANOS MUERTAS. Disponible en http://www.pa.gob.mx/publica/MARCO\%20 LEGAL\%20PDF/LEY\%20DESAM\%20BIE\%20MAN\%20MUER.pdf. Consultada el 03 de agosto de 2014.

LIFFMAN, Paul. 1997. “Representatividad y representación políticas entre los wixáritari (huicholes)”. Ponencia presentada en la 1997 meeting of the Latin American Studies Association, Guadalajara, Jalisco, abril de 1997.

2005. "Fuegos guías y raíces: estructuras cosmológicas y procesos históricos en la territorialidad huichol". Relaciones - Estudios de historia y sociedad, vol. XXVI (101): 52-79.

2012. La territorialidad wixarika y el espacio nacional. Reivindicación indígena en el occidente de México. Zamora:

El Colegio de Michoacán.

LUMHOLTZ, Carl S. 1904. El México desconocido. Cinco años de exploración entre las tribus de la Sierra Madre Occidental; en la tierra caliente de Tepic y Jalisco, y entre los tarascos de Michoacán. Vol Il. Traducción de Balbino Dávalos. New York: Charles scribner's sons.

1986 [1900 y 1904]. El arte simbólico y decorativo de los huicholes.México: INI (serie artes y tradiciones populares; 3).

MEYER, Jean. 1983. “La desamortización de 1856 en Tepic". Relaciones Estudios de historia y sociedad IV (13): 5-30.

1989. El Gran Nayar. México: Universidad de Guadalajara/CEMCA.

MONTEMAYOR, Carlos. s/d. "EI INI". Disponible en www.zapata.com/documents/documents.php3?identifiant=1. Consultado el 26 de septiembre de 2014.

MYERHOFF, Barbara G. 1974. Peyote hunt, the sacred journey of the Huichol Indians. Ithaca: Cornell University Press.

Negrín, Juan. 2005. “Protagonistas del arte huichol”. En Alberto Ruy Sánchez y Margarita Orellana (directores). México: Artes de México: Arte huichol, número 75.

NEURATH, Johannes. 2002. Las fiestas de la Casa Grande: procesos rituales, cosmovisión y estructura social en una comunidad huichola. México: Instituto Nacional de Antropología e Historia/ Universidad de Guadalajara.

2005. "Máscaras enmascaradas, indígenas, mestizos y dioses indígenas mestizos". Relaciones Estudios de historia y sociedad XXVI (101): 22-50. de México.

(coord.). 2007. Artes de México. 85, Arte antiguo cora y huichol: la colección de Konrad T. Preuss. México: Artes

2011. "Ambivalencias del poder y del don en el sistema político-ritual wixarika". In: B. Alcántara Rojas; F. Navarrete Linares (org). Los pueblos amerindios más allá del Estado, México: UNAM. 
; PACHECO BRIBIESCA, Ricardo Claudio. S/d. Atlas de las culturas del agua en América Latina y El Caribe. Pueblos Indígenas de México y agua: huicholes (wixarika). Disponible en http://www.unesco.org.uy/phi/aguaycultura/fileadmin/ phi/aguaycultura/Mexico/05_Huicholes.pdf. Consultado el 18 de septiembre de 2014

PEÑALOZA, Patricia. "El museo debe provocar un cambio de conducta, despertar inquietudes: Alfonso Soto". Archivo de Noticias: La Cultura Sala de Prensa. México. Consejo Nacional para la Cultura y las Artes, 14 de julio del 2001.

PÉREZ RUIZ, Maya Lorena. 2005. “La comunidad indígena contemporánea. Límites fronteras y relaciones interétnicas”. In: M. Lisbona (coord). La comunidad a debate. Reflexiones sobre el concepto de comunidad en el México contemporáneo. Zamora: COLMICH/ Universidad de Ciencias y Artes de Chiapas.

PONCE, fray Alonso. 1976. Relación breve y verdadera de algunas cosas de las muchas que sucedieron al padre Fray Alonso Ponce en las Provincias de la Nueva España, siendo comisario general de aquellas partes, Escritas por dos religiosos, sus compañeros. México: UNAM.

PRATT, Mary Louise. 1996. "Apocalipsis en los Andes: zonas de contacto y lucha por el poder interpretativo". Conferencia pronunciada en el Banco Interamericano de Desarrollo en Washington, D.C., el 29 de marzo de 1996, en el marco del Programa de Conferencias del Centro Cultural del BID. Disponible en http://publications.iadb.org/bitstream/ handle/11319/6142/Apocalipsis $\% 20$ en $\% 20$ los $\% 20$ Andes $\% 3 A \% 20$ zonas $\% 20$ de $\% 20$ contacto $\% 20 y \% 20 l u c h a \% 20$ por $\% 20$ el\%20poder\%20interpretativo.pdf?sequence=1. Consultada el 10 de junio de 2015.

PREUSS, Konrad T.1998. Fiesta, literatura y magia en el Nayarit: ensayos sobre coras, huicholes y mexicaneros de Konrad Theodor Preuss. Jesús Jáuregui y Johannes Neurath (comp.). México: INI/ Centro Francés de Estudios Mexicanos y Centroamericanos.

PRICE, Sally. 1989. Primitive art in civilized places. USA: The University of Chicago Press.

RAMÍREZ FLORES, José. 1980. Lenguas indígenas de Jalisco. Guadalajara: Gobierno de Jalisco.

REED, Karen Bárbara. 1972. El INI y los huicholes. México: INI.

RIVERA CUSICANQUI, Silvia. 2010. Ch'ixinakax utxiwa. Una reflexión sobre prácticas y discursos descolonizadores. Buenos Aires: Tinta Limón.

ROJAS, Beatriz. 1992. Los huicholes: documentos históricos. México: INI/CIESAS

1993. Los huicholes en la historia. México: Centro de Estudios Mexicanos y Centroamericanos/ El Colegio de Michoacán/ INI.

ROMO CEDANO, Luis. 2002. “Carl Lumholtz y El México desconocido”. In: M. Ferrer Muñoz (coord.). La imagen del México decimonónico de los visitantes extranjeros: ¿Un estado-nación o un mosaico plurinacional. México; UNAM.

RUIZ MEDRANO, Carlos Rubén. 2014. “EI Real de Minas de Bolaños, Jalisco, en el siglo XVIII: transformaciones territoriales y cambios sociales". Región y Sociedad. Revista del Colegio de Sonora XXVI (60): 191 -227.

SANTOSCOY, Alberto (comp.). 1899. Nayarit. Colección de documentos inéditos, históricos y etnográficos de la sierra del mismo nombre. Guadalajara, Jalisco: Obispado de Tepic.

1986. Obras completas. Tomo II. México: UNED.

SOTO SORIA, Alfonso. 1955. “Los huicholes”. Artes de Mexico 3 (7): 3- 18.

TELLO, Antonio. 1946. Crónica Miscelánea de la Sancta Provincia de Xalisco, libro IV. México. Editorial Font. 
TORRES CONTRERAS, José de Jesús. 2000. El hostigamiento al costumbre huichol: los procesos de hibridación social. Zamora: El Colegio de Michoacán/ Universidad de Guadalajara.

VASCONCELOS, José. 1925. La raza cósmica. Misión de la raza iberoamericana. Notas de viajes a la América del Sur. Madrid: Agencia Mundial de Librería.

VÁZQUEZ OLVERA, Carlos. 2005. Alfonso Soto Soria, museógrafo mexicano. México: Instituto Nacional de Antropología e Historia.

VÁZOUEZ VALLE, Irene. 1987. "Apuntes sobre la música y otras manifestaciones creativas de los nayares". Relaciones Estudios de historia y sociedad 29: 99-120.

WEIGAND, Phil C. 1978. "Contemporary Social and Economic Structure”. In: K. Berrin (ed.). Art of the Huichol Indians. New York: The Fine Arts Museums of San Francisco/ Harry N. Abrams, Inc. Publishers.

1992. "Aculturación diferencial entre los indios huicholes". In Ensayos sobre el Gran Nayar. Entre coras, huicholes y tepehuanos. México: INI/ Centro de Estudios Mexicanos y Centroamericanos de la Embajada de Francia en México/ Colegio de Michoacán, A.C. México, D.F. 1992.

1992. "El papel de los indios huicholes en las revoluciones del Occidente de México". In Ensayos sobre el Gran

Nayar. Entre coras, huicholes y tepehuanos. México: INI/ Centro de Estudios Mexicanos y Centroamericanos de la Embajada de Francia en México/ Colegio de Michoacán, A.C. México, D.F. 1992.

ZINGG, Robert M. 1982 [1938]. Los huicholes. Una tribu de artistas. 2 vols. México: INI. (Clásicos de la Antropología, 12). 


\section{Transformación de la imagen de los Wixaritari (Huicholes) en el imaginario teiwari (mestizo, foráneo)}

\section{RESUMO}

El wixarika - más conocido como huichol - existe en el imaginario teiwari (no wixarika) de distintas maneras. Pero dicha imágenes no emergen de la naturaleza o dictadas por una mano omnipotente que asignó a cada quien prácticas culturales específicas, como suele mirarse inconscientemente aún en ámbitos académicos; sino de un contexto histórico cultural del que ellos y sus "Otros" son actores y producto. En ese sentido, este artículo pretende explicar la transformación de la imagen del wixarika en el imaginario teiwari a través de las problemáticas relaciones que ambas sociedades ha entablado a lo largo de los siglos. Para ello se toma como eje el arte huichol, poderoso referente actual de la identidad wixarika.

PALAVRAS-CHAVE: Identidad wixarika; arte huichol; territorio; teiwari; interculturalidad.

\section{Transformation of the images of the Wixaritari (Huicholes) in teiwari (mixed, foreigner) imaginary}

\section{ABSTRACT}

The Wixarika, better known as Huichol, exists in teiwari (no wixarika) imaginary on different ways. Images, however, cannot be taken as if they emerge from nature or as if they were made by an omnipotent hand who dictates specific cultural practices, as they seem to be unconsciously taken in some academic circles. Images emerge from a cultural-historical context in which they and their "others" are simultaneously actors and products. In this sense, this paper attempts to explain the transformation of wixarika image in the teiwari (no wixarika) collective imagination throughout the problematic relations that both societies have developed over the centuries. In order to do so, the text takes Huichol art, a powerful reference of contemporary wixarika identity, as its central theme.

KEYWORDS: Wixarika identity; Huichol art; territory; teiwari; interculturality. 